\title{
Liderazgo pedagógico crítico: la docencia y la intelectualidad orgánica
}

\author{
Critical and pedagogical leadership: teaching and organic \\ intellectuality.
}

Liderança pedagógica crítica: O ensino e a inteligência orgânica.

\author{
Andrés Ariel Robles-Barrantes \\ Universidad Nacional \\ Heredia, Costa Rica. \\ andres.robles.barrantes@una.cr \\ iD https://orcid.org/0000-0001-6298-4509 \\ Roberto Arguedas Zúñiga \\ Universidad Nacional \\ Heredia, Costa Rica \\ roberto.arguedas.zuniga@una.cr \\ (iD) https://orcid.org/0000-0002-1169-8008
}

Recibido - Received - Recebido: 17/07/2020 Corregido - Revised - Revisado: 01/11/2020 Aceptado - Accepted - Aprovado: 26/11/2020

URL: https://revistas.uned.ac.cr/index.php/innovaciones/article/view/3051

\begin{abstract}
Resumen: El objetivo del presente ensayo académico es promover el ejercicio de un liderazgo pedagógico crítico que representa un proceso participativo, dialógico, emancipador, contextualizado y transformador donde las personas docentes pueden contribuir, como intelectuales orgánicas, generando respuestas a las necesidades de quienes son más vulnerables y que se encuentran directamente relacionadas al contexto educativo. El abordaje metodológico del presente ensayo parte del estudio del significado de ser docente, el liderazgo, y el liderazgo pedagógico para posteriormente construir el concepto del liderazgo pedagógico crítico. Además, examina competencias que conjugan las implicaciones de la labor docente y su alcance en la pedagogía, a la vez que cuestiona el rol docente bajo el foco de la intelectualidad orgánica. Esta reivindicación de la docencia implica ir más allá de los impactos del modelo económico imperante, la función del Estado en el contexto educativo y las exigencias sistemáticas de modelos educativos que condicionan la función y formación profesional a favor de una perspectiva meramente técnica. Se concluye que desde el entendimiento del contexto demarcado por el neoliberalismo en donde se desenvuelve la labor de las personas docentes en Latinoamérica es posible percibir los motivos por los cuales la promoción de su liderazgo como un mecanismo de transformación social, mas no desde un discurso oficial o impulsado por algún sistema educativo. El liderazgo pedagógico crítico debe estar construido desde una concepción pedagógica y un esfuerzo colectivo, más allá de prácticas individuales, proceso en el que la intelectualidad orgánica se encuentra como instrumento para alcanzar la meta.
\end{abstract}

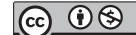


Palabras clave: Docencia; educación; liderazgo; pedagogía; pensamiento crítico.

Abstract: This academic essay aims to promote the exercise of critical and pedagogical leadership. It is understood that it implies creating participative processes that are dialogic, emancipating, contextualized and transforming, where teachers can contribute as organic intellectuals by generating answers for the needs of those are more vulnerable and who find themselves directly involved in the educational context. The present essay's methodological approach has its origins in studying what it means to be a teacher, what is leadership, and pedagogical leadership to build the concept of critical pedagogical leadership. Also, it examines the competencies that combine the implications of teaching and its scope in pedagogy while questioning the teaching role under the focus of organic intellectuality. This teaching vindication implies going beyond the impacts of the prevailing economic model, the role of the State in the educational context, and the systematic demands of educational models that condition the role and professional training in favor of a merely technical perspective. In conclusion, understanding the context marked by neoliberalism in which Latin American teachers' work unfolds makes it possible to perceive the reasons for promoting their leadership as a social transformation mechanism, but not from the official discourse and nor driven by an educational system. Critical pedagogical leadership must be built from a pedagogical conception and a collective effort, beyond individual practices, a process in which the organic intellectuality is found as an instrument to achieve the goal.

Keywords: teaching, education, leadership, pedagogy, critical thinking.

Resumo: O objetivo deste ensaio acadêmico é promover o exercício de uma liderança pedagógica crítica que represente um processo participativo dialógico, emancipatório, contextualizado e transformador onde os professores possam contribuir, como intelectuais orgânicos, gerando respostas às necessidades daqueles que são mais vulneráveis e que estão diretamente relacionados com o contexto educacional. A abordagem metodológica do presente ensaio parte do estudo do significado de ser um professor, liderança e liderança pedagógica para mais tarde construir o conceito de liderança pedagógica crítica. Além disso, ela examina as competências que combinam as implicações do trabalho docente e seu escopo na pedagogia, enquanto questiona o papel docente sob o foco da intelligentsia orgânica. Esta demanda de ensino implica em ir além dos impactos do modelo econômico predominante, do papel do Estado no contexto educacional e das exigências sistemáticas dos modelos educacionais que condicionam a função e a formação profissional em favor de uma perspectiva meramente técnica. Concluise que a partir do entendimento do contexto demarcado pelo neoliberalismo em que se desenvolve o trabalho dos professores na América Latina, é possível perceber as razões pelas quais a promoção de sua liderança é um mecanismo de transformação social, mas não a partir de um discurso oficial ou promovido por qualquer sistema educacional. A liderança pedagógica crítica deve ser construída a partir de uma concepção pedagógica e de um esforço coletivo, além das práticas individuais, um processo no qual a intelligentsia orgânica é encontrada como um instrumento para atingir o objetivo.

Palavras-chave: Docência; educação; liderança; pedagogia; pensamento crítico. 


\section{INTRODUCCIÓN}

Comprender el rol de la persona educadora se corresponde con entender una serie de dinámicas que involucran su labor. La docencia representa, sin lugar a dudas, la columna vertebral del proceso educativo donde su función amerita, más que nunca, la reivindicación constante de su desempeño e implicaciones. Ante las evidentes amenazas a las que sistemáticamente se someten las personas docentes, se vuelve fundamental comprender cuál es el rol que poseen y cuál es la importancia de su labor. El proceso inicia por una autoevaluación del desempeño: ¿qué hacen las personas docentes dentro de las aulas?, ¿a qué valores y ordenamientos filosóficos, ideológicos, políticos y culturales responden?, ¿son conscientes de la función que desarrollamos dentro del sistema educativo?, interrogantes que requieren un análisis y que, partiendo de ahí, logran plantear el perfil que debería desempeñar una persona docente en este momento histórico.

Para los efectos del planteamiento que propone el ensayo académico es necesario clarificar la construcción conceptual que tiene tanto la docencia como el liderazgo. Ambos conceptos constituyen la propuesta central de un liderazgo crítico en función de la labor educativa, basado en un enfoque pedagógico como área de estudio. Se entiende que la docencia simboliza un oficio de profunda legitimidad y dignidad social, que no puede ser desvinculada de un origen de servicio e incidencia en los contextos en los que se desenvuelve. Mientras que el liderazgo, a pesar de ser un concepto constituido formalmente desde enfoques empresariales y con fines económicos, es posible que pueda ser contemplado como un instrumento práctico para la ejecución, adaptación y transformación de procesos más allá del ámbito empresarial, que incluso pueden incluir el espacio educativo y por ende también la docencia, dando origen a lo que puede ser entendido como un liderazgo pedagógico.

Para una mayor claridad en este sentido, es oportuno comprender los aportes de los conceptos expuestos y las corrientes de pensamiento que representan. De esta forma, el objetivo primordial del ensayo es brindar el fundamento teórico necesario para la construcción del concepto de liderazgo pedagógico crítico para su posterior aplicación en la realidad educativa.

\section{DESARROLLO}

\section{La persona docente: conceptualización y competencias}

Sobre la conceptualización del término docencia es posible encontrar diferentes aportes sobre su construcción. Un primer acercamiento podría llevarnos al entendimiento de la docencia como una profesión, esto desde la lógica de conocimiento formalizado. Sin embargo, es trascendental comprender que más que una profesión, la docencia implica una vocación de trabajo en función de lo colectivo, la comunidad, es decir, al servicio de las personas. Sobre la apreciación, Duarte (2007) apunta que la persona "docente asume una obligación que más allá de la simple ejecución de una actividad, implica un compromiso social y una responsabilidad como profesional" (p. 33) y que, en un sentido ético, debe usar "al máximo sus propias estrategias sin ser corrompido por los estándares lineales y alienantes" (Cerquera-Flórez, Corredor-Medina, Cuero-Mosquera, Rivera-Sierra, y Castro-Pérez, 2016, p. 313). El compromiso social representa más que la labor individual, y comprende la búsqueda de un bienestar común que no puede responder a los intereses particulares, es decir "la acción entre docente y estudiante va más allá del propio interés personal y da la oportunidad de entregarse seriamente en una causa educacional, que trasciende a quien la desempeña" (Castillo, 2010, p. 902). Desde ahí es posible percibir diferentes funciones que deben realizar las personas docentes para visualizar sus alcances.

\section{(ब) (1)}


Las funciones desarrolladas por las personas docentes contemplan diferentes dimensiones que involucran una labor cotidiana constante. Castillo (2010) las aborda describiéndolas como competencias en diferentes ámbitos de su desempeño. Primeramente, plantea las competencias en la disciplina, relacionadas al manejo de la disciplina que desarrolla la persona docente en particular y su conocimiento sobre el área de estudio que desempeña. Como segundo campo, las competencias en la organización de contenidos, implican contemplar las percepciones de las personas estudiantes, los diferentes actores envueltos en el proceso de estudio, la realidad del contexto en que se desenvuelven para así poder planificar cómo se abordan los contenidos de manera significativa y realista para la comunidad aprendiente.

En tercer orden, las competencias relacionadas con la variedad del aprendizaje, implican valorar las diferentes formas o estilos de aprendizaje que tienen las personas estudiantes para impulsar los procesos de mediación. Seguidamente, las competencias en la incorporación de nuevas tecnologías de la comunicación y de la información, las cuales se encuentran relacionadas a los retos en cuanto a la incorporación de una era tecnológica que está compenetrada con todos los procesos sociales actuales donde los métodos de aprendizaje no son una excepción. Como quinto componente agrega las competencias en evaluación, las mismas responden a la capacidad de adaptar, diseñar y modificar los procesos evaluativos del conocimiento. Finalmente, las competencias en el área de ética en la acción educativa, las cuales simbolizan la comprensión del rol ético y social que desarrollan las personas en los procesos educativos (Castillo, 2010). Todas las competencias conjugan las implicaciones de la labor docente y el alcance de su desempeño.

\section{Liderazgo: conceptualización y funciones}

Sobre el liderazgo es importante primeramente identificar sus principales influencias en términos de la construcción de su contenido conceptual. Tal vez el origen del liderazgo se remonte al nacimiento mismo de la estructuración social, tal cual se conoce hoy en día. Debido a que forma parte de una de las habilidades humanas que parecen desarrollarse incluso de forma natural. Podrían también identificarse menciones al término desde el ámbito militar, donde, por ejemplo, en un texto como El Arte de la Guerra (Sun, 2016) es posible denotar algunos elementos del liderazgo. Sin embargo, la mayoría de las definiciones encuentran similitudes con los planteamientos relacionados a la dirección, la influencia, la toma de decisiones y el alcance de objetivos. Giraldo y Naranjo (2014) aportan que "la gran mayoría (por no decir todos) de los estudiosos del tema lo definen como, una interacción entre el líder y sus seguidores para lograr cumplir los logros, objetivos y metas propuestos" (p. 15). Dicho de otra manera, las diferentes definiciones que existen sobre el liderazgo concuerdan con una misma columna vertebral de lo que representa este concepto.

Teniendo claro al menos las implicaciones del liderazgo, es posible discutir sus alcances en términos de una organización. Existen elementos necesarios que una persona requiere para que pueda ser considerada con la capacidad de liderar proceso, los elementos pueden ser: la proactividad, la creatividad, la influencia o idealización, el trabajo en equipo y la comunicación asertiva. Se puede decir que lidera quien:

[...] por medio de su interacción e influencia sobre un grupo de personas (seguidores), y gracias a cualidades como la comunicación asertiva, la creatividad, la proactividad y el trabajo en equipo, es capaz de lograr las metas y objetivos que comparte con sus seguidores. (Gómez, 2008, citado en Giraldo y Naranjo, 2014, p. 16)

A partir de un análisis de esta definición, se puede comprender que quien lidera cuenta con una serie de capacidades que facilitan los procesos de organización y el alcance de los objetivos que se planteen. El liderazgo puede ser llevado a diferentes campos de estudio y de esta forma lograr alcanzar con mayor eficacia los objetivos planteados tanto desde una empresa privada o fuerza militar como de una institución 
pública o movimiento comunitario. Lo anterior, es posible incluso en el ámbito educativo donde la adaptación del liderazgo a este campo tendría la oportunidad de generar diferentes aportes a los procesos educativos partiendo de la labor que realizan las personas docentes. Por ejemplo, Solano Gutiérrez y Campos Céspedes (2014), tras consultar a 911 estudiantes de carreras de Educación, hallaron que dentro de las competencias sistémicas se encuentra en primer lugar la capacidad emprendedora (creatividad e innovación), seguido de la organización (actualización y capacitación) y, por último, el liderazgo como la competencia menos valorada. Por estas razones, es necesario llevar el liderazgo a la pedagogía para su desarrollo y entendimiento conceptual.

\section{Liderazgo pedagógico}

Entender el liderazgo más allá de una estrategia administrativa-comercial representa la reconstrucción de un concepto. Implica una deconstrucción y transformación de sus propósitos para vincularlos a una mirada desde la pedagogía. Primeramente, debe existir un rompimiento con las lógicas del éxito y alcance de objetivos en función del mercado o la productividad en un sentido económico para avanzar al entendimiento de un proceso al servicio de lo colectivo, prácticamente un objetivo común, lo cual reafirma Bolívar (2015) al relatar que "en lugar de limitarse a la gestión, se centra en hacer de la escuela o instituto un proyecto de acción colectiva al servicio de proporcionar la mejor educación para todos" (p. 24). En síntesis, no se debe confundir la gestión educativa con el liderazgo pedagógico (ver Bolívar, 2015) o el liderazgo centrado en el curriculum, como plantea Rodríguez-Molina (2011), que se enfoca en el cuerpo docente, su praxis, gestión curricular, y monitoreo del aprendizaje, por ejemplo. Tampoco se puede desestimar el vínculo positivo que debe existir entre liderazgo pedagógico y una buena gestión educativa. Lo cierto es que esa mirada desde la pedagogía debe apreciar la importancia de lo común más allá de lo individual, la relevancia de que en una comunidad de aprendizajes y saberes se avance de la mano de un esfuerzo colectivo nutrido por la solidaridad, inclusividad y equidad. De este modo, el papel no es solamente limitado a la docencia; no obstante, en función del liderazgo pedagógico, es la docencia la que debe asumir el rol citado, puesto que son quienes "sitúa[n] como brújula de acción la mejora de los aprendizajes del alumno" (p. 24).

Si bien el liderazgo pedagógico corresponde aún más a la docencia, no debe entenderse como un esfuerzo aislado o individual. Si el fin es mejorar la visión, praxis docente y procesos de aprendizaje, resultan necesarias dos acciones: la revolución de parte de la docencia y la articulación pedagógica con la administración. A priori, podría parecer antagónico o contradictorio que exista un modelo administrativo para que quienes lo asuman luego generen cambios en su contra. Sin embargo, debe entenderse que esta revolución es propia de quien asume un liderazgo pedagógico, ya que en su praxis se caracteriza por propiciar cambios, y ser una persona autocrítica, consciente de los cambios sociales e innovadora (Barrantes-Elizondo y Olivares-Garita, 2016). Por último, si su fin es buscar que la administración “[...] aprenda a hacerlo mejor, sería contradictorio que dependa de un líder... [y] se requiere pasar del líder formal a un liderazgo compartido o distribuido" (Bolívar, 2015, p. 24), que se logra a partir del diálogo propio del liderazgo pedagógico.

\section{Liderazgo pedagógico crítico: concepto en construcción}

A partir de esta noción del liderazgo, buscamos nutrir una corriente epistemológica desde un enfoque diferenciador, uno que invite al entendimiento de su entorno y la transformación de forma crítica de las realidades enfrentadas en el ámbito educativo, comunitario y social. El liderazgo pedagógico comprendido e implementado, desde una mirada crítica constituye la propuesta central de este ensayo académico, el 
cual pretende aportar a la construcción del concepto con el fin de enriquecer la forma en que las personas docentes asumen los procesos pedagógicos. Como características elementales que se desarrollarán, es fundamental plantear el entendimiento del liderazgo pedagógico crítico sustentado desde tres pilares: un proceso participativo y dialógico, un proceso emancipador y contextualizado y, finalmente, un proceso transformador. La fundamentación teórica en estas tres aristas es la que podrá llevar a la práctica el enfoque de liderazgo con mayor eficacia, al hacer una diferenciación necesaria.

El liderazgo pedagógico crítico es un proceso participativo y dialógico. El entender el liderazgo desde una mirada participativa representa un esfuerzo por concebir su construcción desde la horizontalidad y distribución del poder. Un liderazgo que se desenvuelve desde el involucramiento de las personas que se encuentran entrelazadas en los procesos pedagógicos que se están llevando a cabo. La participación se encuentra a su vez promovida por un diálogo constante y significativo. En otras palabras, es pasar de las prácticas que solo implican comunicar de manera unidireccional como en liderazgos tradicionales, a un esfuerzo por generar comunicación de manera multidireccional. Sobre esto, Freire (1987) reflexiona sobre la "actitud dialogal que los coordinadores deben adquirir para realmente educar y no 'domesticar'. Porque siendo el diálogo una relación yo-tú, es necesariamente una relación de dos sujetos" (p. 113). Es decir, es la persona docente quien abandona el rol de solamente dar órdenes, por uno que discute, propone y permite la vinculación de personas estudiantes, y otras que integren la comunidad de aprendizajes en su labor y toma de decisiones.

El liderazgo pedagógico crítico es un proceso contextualizado y emancipador. El enfoque surge de la realidad de la comunidad, sus preocupaciones y necesidades, para en conjunto con ella plantear soluciones y transformaciones a las vivencias que pueden estar oprimiendo o afectando su crecimiento intelectual, cultural, social y económico. El liderazgo debe enriquecerse de la realidad que viven las personas que integran el proceso educativo. lo anterior, partiendo del intercambio de saberes que se suman, no desde una mirada verticalista, sino más bien integradora, incluyendo la realidad que viven las personas cada día en su mundo real e inmediato. Freire (1987) indica la necesidad de "una educación valiente, que discuta con el hombre común su derecho a aquella participación. Una educación que lleve al hombre a una nueva posición frente a los problemas de su tiempo y de su espacio" (p. 88). Un liderazgo pedagógico crítico debe contribuir a que las personas de la comunidad educativa identifiquen las problemáticas que les sujetan, esos hilos del poder que les dominan, su posición política en su contexto social, logrando que puedan emanciparse y comprender lo que enfrentan para su posterior transformación. El proceso implica que exista un liderazgo sustentado por componentes intelectuales al servicio comunitario, todo promovido desde la institución educativa como centro motor de conocimiento.

El liderazgo pedagógico crítico como un proceso transformador simboliza que el liderazgo debe llevar a la acción, no puede ser simplemente una corriente descriptiva que se encuentra a la expectativa de los hechos. Por lo tanto, debe comprometerse con la generación de cambios en una búsqueda constante por la equidad y la justicia. Freire (1985) retoma que "es necesario trascender todos los tipos de educación, para alcanzar otro, uno en el que conocer y transformar la realidad son prerrequisitos recíprocos" (p. 118). A partir de identificar las diferentes circunstancias que pueden ser fuentes de opresión o que limiten la libertad de alguna forma, es un liderazgo proactivo, creador de alternativas, que busca de forma constante y comprometida romper con lo que se requiera para construir un nuevo paradigma. Desde una clase, es la docencia que invita a romper esquemas y levantar desde posturas políticas espacios de mayor solidaridad y búsqueda permanente del bien común por encima de cualquier perspectiva individual.

Para alcanzar este tipo de liderazgo se debe tomar una posición en la que la labor intelectual que se realiza desde la docencia contribuya a los objetivos comunes de las diferentes personas envueltas en el proceso que se está liderando. Para una mayor comprensión sobre esta relación es necesario retomar el concepto de intelectualidad orgánica. 


\section{La intelectualidad orgánica en la docencia}

Para entender a la persona desde su intelectualidad orgánica se debe partir de una de dos premisas de la formación de los tipos de intelectuales del pensamiento de Gramsci (1967), de las cuales se subraya lo siguiente:

Todo grupo social que surge sobre la base original de una función esencial en el mundo de la producción económica, establece junto a él, orgánicamente, uno o más tipos de intelectuales que le dan homogeneidad no sólo en el campo económico, sino también en el social y político. (p. 21)

Es decir, la formación de las personas intelectuales y sus diversos tipos, según su rol en el funcionamiento de la sociedad, responden en pro o en contra de una hegemonía dominante. Al estar bajo la dominación, entran en una cadena de jerarquizaciones que les subyuga a cumplir funciones técnicas, productivas u organizativas que son el reflejo de pertenecer a una superior. De allí que, se visualiza el concepto de una persona intelectual como aquella que adquiere orgánicamente una forma o "'masa más o menos amorfa" (Giglioli, 1996, p. 31) dentro de un cuerpo organizado. Desde la perspectiva de Gramsci, esto podría ser según lo requiera la clase dominante o hegemónica. En la misma línea, es este poderío hegemónico el que "tiene a su disposición los medios para la producción material [que] dispone [...] de los medios para la producción espiritual, lo que hace que se le sometan [...] las ideas de quienes carecen de los medios necesarios para producir espiritualmente" (Marx y Engels, 1974, p. 50).

No obstante, las mismas condiciones sitúan a las personas intelectuales orgánicas en una posición donde pueden mediar como agentes dentro de espacios políticos y sociales, ante las diferentes clases de poder, al encargarse "de la articulación entre estructura y superestructura en el bloque histórico y de la articulación entre sociedad política y sociedad civil (entre dominación y hegemonía) en el ámbito de la superestructura" (Giglioli, 1996, p. 32). Es en esta superestructura del aparato social que deberán organizarse para afrontar o, como mínimo, participar en el constante flujo de poder, como personas revolucionarias o partidarias del sistema.

En la docencia, toma rigor la labor de la persona docente como agente sociopolítico, liberadora y transformadora. Recuerda Gramsci (1967) que "el nexo instrucción-educación en la escuela solo puede representarlo el trabajo vivo del maestro" (p. 127). Son las personas docentes quienes deben conocer la realidad de sus estudiantes y contexto, a nivel micro, meso y macro de la misma forma que sus implicaciones. De esta forma, intentar alejarse de la instrucción como técnica que "no tendrá como éxito el lograr que [los estudiantes] sean más cultos" sino más bien que "la escuela lo[s] formará con escrúpulo y conciencia burocrática y mecánica" (p. 128). Esta reflexión sobre la persona discente como pasiva, receptora y mecanizada es aún más evidente en la aplicación de exámenes, de lo cual Gramsci (1967) advirtió deberían abolirse, debido a que desvirtúan el propósito del examen ya que "Para cualquier profesor que examine, una 'fecha' es siempre una fecha, y una 'definición', una definición; pero ¿y un juicio y un análisis estético o filosófico?" (p. 128). Un caso concreto es la enseñanza de las lenguas o idiomas, que provienen de la Escuela de Filosofía y Letras; Gramsci (1967) criticaba que no se aprendía un idioma para ajustarse a un puesto técnico-profesional, sino para ahondar en las complejidades que regían el porvenir de las sociedades en donde se practicaba la lengua, como mirada externa al entendimiento del acervo cultural e interna al desarrollo de la propia personalidad, carácter y refinamiento del ser. Es en ésta perspectiva de la intelectualidad orgánica que se pierde la esencia del nexo instrucción-educación al tornarse anacrónico cuando no existe un hilo conductor entre la realidad del ser y la educación en su adolescencia, y menos en su infancia, que se extiende más allá de la relación teórica-práctica que posiciona el trabajo como "orden natural" de la actividad de la persona, especialmente en el contexto capitalista. 
Sobre la organicidad al servicio de un bien común y contraria a los intereses individuales de una persona, clase o sistema, debe entenderse como un proceso en respuesta a los intereses colectivos. Nuevamente, Gramsci (2014) determina que "esa organicidad solo podría conseguirse si los intelectuales hubieran elaborado y hecho coherente los principios y los problemas que planteaban aquellas masas con su actividad práctica, constituyendo así, entre unos y otros, un bloque cultural y social" (p. 370). Este bloque cultural y social debe partir de un esfuerzo colectivo contra cualquier imposición hegemónica.

\section{El contexto de la docencia en una realidad neoliberal}

La tendencia de la amenaza neoliberal por despotricar contra la educación pública, en una búsqueda por su privatización y con el discurso de reducir el gasto público (Torres, 2008) está impregnada en Latinoamérica (López-Guerra y Flores, 2006), comenzando en Chile, y pasando por países como Argentina, Brasil, Venezuela, Colombia, El Salvador, Costa Rica, México, entre otros. Se ha proliferado rápidamente y convertido en un principio organizativo insertado en muchas sociedades, tan universalmente que a menudo pasa desapercibido (Enser-Kananen et al., 2017). Sin embargo, siempre ha seguido un patrón definido, aduciendo que el sistema educativo público ha fracasado y ofreciendo como única solución la reducción del rol del Estado y la inversión en educación; es decir, se cuestiona lo público y se critica al "Estado como fuente de todos los derroches y freno de la prosperidad" (Díez-Gutiérrez, 2016, p. 165) donde "el subsidio del paro y las ayudas sociales mantienen a la gente dependiente del Estado [y] la gratuidad de los estudios empuja a la vagancia" (p. 10).

El rol del Estado, regulador y desregulador (Rodríguez-Mancilla, 2018; Magalhães et al., 2020), actuando sobre determinaciones de terceros, ha llevado a "fortalecer la iniciativa privada, contribuyendo directamente al sostenimiento de la desigualdad social" (Magalhães et al., 2020, p. 51), caso del que tampoco escapa la realidad de Costa Rica (Solano-Muñoz, 2010). En esta línea, se busca privatizar los servicios, privatizar el sistema educativo e imponer una agenda particular politizada (Puiggrós, 1996, Magalhães et al., 2020). Esta ideología implica convertir a la persona "en un animal laborans, hasta el cansancio, hasta alcanzar la libertad donde la "explotación por otros queda interiorizada" (Díez-Gutiérrez, 2016, p. 166). Un esfuerzo que sin duda se puede visualizar en la reducción de la docencia a una función meramente técnica y burocrática, y no el ejercicio de un liderazgo pedagógico nutrido de una labor intelectual en función de las necesidades colectivas.

Por ejemplo, la "producción" del profesorado, en Argentina y Brasil, y su formación expedita no escapa a esta realidad capitalista que, desvirtuada de una base teórica, sustenta el quehacer docente por una formación y praxis más operativa, o más técnica (Magalhães et al., 2020). Agregado a la formación docente, Torres (2008) afirma que la creación de diferentes estándares de excelencia académica internacional no ha logrado mejorar la educación, sino más bien ser usado como instrumento de control político. Para citar otro ejemplo, en Colombia se vislumbra un contexto similar:

Los estándares internacionales rigen y una educación humana y crítica queda difusa en el escenario cuando los intereses son otros. Se mantiene la necesidad de una educación para el trabajo y reproducción de la mano de obra propicia para las multinacionales que han llegado y seguirán llegando al país. (Galindo, Gómez y Rodríguez, 2015, pp. 86-87)

Además, debido a los desajustes financieros y fiscales, las deudas del país y la reducción de inversión en educación llevan a los centros de educación superior a buscar formas de autofinanciación (Galindo et al., 2015), para contraer el gasto público, a menudo a través de la elevación de los costos de matrícula o estudios, lo cual, en el caso de Chile, paulatinamente disminuyó la matrícula en centros educativos públicos 
e incrementó en los centros educativos privados (Santa Cruz-Grau y Olmedo, 2012). En esta afectación, también las personas estudiantes pierden, especialmente cuando deben basar sus decisiones en conceptos mercantiles, de demanda y oferta; es decir, deben escoger una carrera que luego les permita obtener recursos, más no según el gusto, preferencia, amor, pasión y afinidad (Galindo et. al, 2015).

\section{REFLEXIÓN Y SÍNTESIS GENERAL}

El análisis realizado en el ensayo académico parte del entendimiento del contexto demarcado por el neoliberalismo en donde se desenvuelve la labor de las personas docentes. En Latinoamérica es posible percibir los motivos por los cuales la promoción de su liderazgo como un mecanismo de transformación social no es algo que vaya a llegar desde un discurso oficial o impulsado por algún sistema educativo. Tal como lo indicó Freire (1985): "Sería extremadamente ingenuo pretender que las clases dominantes desarrollen un tipo de educación que permitiera a las clases sometidas percibir críticamente las injusticias sociales" (p. 115). Sin embargo, el ejercicio de la docencia desde un espacio público al servicio de las personas, especialmente quienes se encuentran en los sectores más vulnerabilizados, requiere de un acercamiento con las exigencias de esas comunidades, las masas, que están estrechamente vinculadas a la labor que se realiza en los centros educativos. Un esfuerzo que puede construir puentes para un intercambio de saberes entre diferentes agentes, permitiendo el desarrollo de un liderazgo pedagógico crítico que aporte de forma orgánica en las transformaciones necesarias en los diferentes contextos sociales. La labor mencionada parece que tendrá que ser asumida, más que por una disposición sistemática, por un esfuerzo comprometido de las personas docentes con los espacios en los que se desenvuelven y los sectores que lo requieren.

El liderazgo para lograr incidir de forma contundente debe estar construido desde una concepción pedagógica, lo cual implica una labor integradora que pueda contemplar un aporte institucional a partir de los esfuerzos realizados de forma conjunta entre diferentes sectores de la institución. Un esfuerzo colectivo que pueda ver más allá de prácticas individuales y la competencia impregnada en los sistemas educativos como respuesta al modelo económico imperante.

El sistema educativo de Finlandia es uno de los ejemplos, que incentiva a las personas docentes a compartir, y no competir, sus recursos, ideas y pericia (Robinson y Aronica, 2016). Para esto es crucial el crear una comunidad de aprendizaje, y de no existir una comunidad de aprendizaje colaborativo y colegiado entre personas docentes, no se podría esperar que lo haya entre estudiantes (Sarason, 1990, como se citó en Grossman, Wineburg, y Woolworth, 2001). Al mismo tiempo, se debe discernir bajo qué contextos o situaciones la colegialidad puede transformar la enseñanza, en el choque de prácticas tradicionales con aquellas innovadoras (Little, 2003), mediante comunidades de aprendizaje que focalicen tópicos pedagógicos y perspectivas que influyen y enriquecen los procesos educativos (Contreras, 2016). Entonces, toma mayor importancia el no solo ser una persona consciente, sino que además propulsora del liderazgo pedagógico crítico como una propuesta alternativa a modelos basados en enfoques individualistas para concentrarse en el alcance de objetivos donde las personas docentes trabajan de forma conjunta, contribuyendo en un esfuerzo transformador impulsado tanto por personas estudiantes como docentes.

Para lograr una transformación educativa significativa se requiere de al menos tres fundamentos claves: una valoración crítica del estado actual de un fenómeno, una cosmovisión de cómo debería ser, y una teoría de cambio que marque las pautas por seguir (Robinson y Aronica, 2016). En este sentido es importante valorar el contexto neoliberal en el cual se encuentra inmersa la educación, que puede y debe cambiar en función del liderazgo pedagógico por medio de una interacción promovida por el diálogo discente-docente que concientiza y enmarca un pensamiento que fomenta el liderazgo pedagógico crítico. 
Las capacidades de las personas docentes se fortalecen a partir de una relación constante entre los diferentes actores envueltos en la comunidad educativa. En el corazón del proceso pedagógico se encuentra la relación estudiante-docente (Robinson y Aronica, 2016) que va más allá de los modelos y apreciaciones tradicionales, donde más que una relación dicotómica, opuesta y jerarquizada se representa un intercambio de percepciones, ideas y saberes. Un diálogo multidireccional en donde los roles se diluyen para aportar a procesos creativos y transformadores.

En los procesos educativos, las personas docentes tienen un papel protagónico que claramente demarca e influye en la realidad no solo de las personas con quienes trabajan, sino que también en su entorno. Nietzsche (1999) indica que "existen otros medios para encontrarse a sí mismo, para salir del aturdimiento en el que habitualmente nos agitamos como envueltos en una densa niebla, pero no conozco ninguno mejor que el de recordar a nuestros propios educadores y formadores" (p. 3), haciendo referencia a esa innegable labor que debe ser legitimada a partir de su compromiso con la construcción del conocimiento y el análisis crítico de diversas realidades, imposiciones y criterios absolutos que representan en muchas ocasiones la densa niebla que describe Nietzsche. Sin embargo, el mismo autor retoma que el ejemplo tiene que llegar por medio de una realidad práctica, "y no simplemente por el de los libros, esto es, justo como enseñaban los filósofos griegos, con su fisonomía, su actitud, su atuendo, su alimentación, con sus costumbres antes que con sus palabras o con sus escritos" (Nietzsche, 1999, p. 4), donde se hace referencia a esa práctica consecuente que debe existir con el discurso de la persona docente. En otras palabras, la persona docente para encontrar legitimidad no habla solamente de transformar el mundo en sus clases, sino que transforma el mundo en conjunto con las personas estudiantes y demás agentes de la comunidad de saberes.

Resulta necesario analizar la forma en que ha sido concebido el perfil de las personas docentes, su formación y la evaluación de su desempeño desde la oficialidad de las instituciones y entidades internacionales que impulsan normativas en cuanto a la educación. Solano y Campos (2014) abarcaron competencias esenciales, sistémicas, interpersonales, e instrumentales donde destacaron componentes como el uso de las TIC, resistencia y adaptación al entorno, sentido ético, orientación hacia el aprendizaje, comunicación interpersonal, trabajo en equipo, diversidad e interculturalidad tratamiento de conflictos y negociación, actualización y capacitación, innovación y creatividad, liderazgo y pensamiento crítico; curiosamente, un espíritu emprendedor y la toma de decisiones fueron desvalorizados.

Lo anterior, refleja cómo la labor docente se reduce a un ejercicio meramente técnico en el que se le otorga la función de seguir directrices establecidas por medio de currículos disciplinares, velar por el cumplimiento de los mismos por parte de sus estudiantes y comunicar los resultados. En esta línea, no se puede obviar cuáles directrices superiores organizativas le confieren un estado operativamente técnico a la persona docente. A partir de ahí, la formación de las personas docentes se reduce a garantizar estas funciones, sin ir más allá del desenvolvimiento meramente tecnócrata. En consecuencia, con esto, la persona docente es evaluada, obteniendo una valoración positiva siempre que cumpla con lo establecido. Tal es el caso que expone Cuevas-Cajiga y Moreno-Olivos (2016) sobre políticas de evaluación docente que inciden en la permanencia de las personas docentes de educación básica en el que en "las acciones vigentes priman las funciones administrativas y de control antes que las funciones formativas de la evaluación docente" (p. 17).

No obstante, no se puede culpar al "sistema" de todo problema, ya que, como advierte Robinson y Aronica (2016), la educación es aquello que ocurre entre discentes y docentes; por ende, la docencia es el "sistema". Así, es posible concluir que el interés por vaciar de contenido la docencia implica un alejamiento con posturas como las promovidas desde un liderazgo pedagógico crítico, lo que constituye a este planteamiento en un modelo altamente reivindicativo y emancipador a partir simplemente de su puesta en práctica.

Lo anterior, involucra una labor reivindicativa en la que la docencia sea vista como un proceso para que la intelectualidad orgánica de las personas docentes sea puesta al servicio de las transformaciones que 
necesita la realidad social en la que se envuelven. Es decir, la búsqueda constante porque la educación tenga la posibilidad de construir una sociedad con menos desigualdades e inequidades puede remitir a un proceso en el que la intelectualidad orgánica se encuentra como instrumento para alcanzar la meta.

Desde el ámbito educativo, es posible concluir sobre un debate abierto en torno a la construcción del concepto de liderazgo pedagógico crítico. Más allá de su fundamentación teórica es necesario seguir analizando sobre su instrumentalización práctica. Es decir, ¿cómo llevar a la práctica este estilo de liderazgo?, ¿cuáles son los resultados directos del liderazgo?, ¿cuáles actores desenvuelven un rol protagónico en el liderazgo pedagógico crítico? Desde esas interrogantes es posible la generación de aportes investigativos que inviten a conocer los alcances de la pedagogía crítica y a partir de los mismos poder abrir nuevos debates que lleven al posicionamiento de diferentes paradigmas educativos y formas de entender y resignificar la educación.

\section{REFERENCIAS}

Barrantes-Elizondo, L. y Olivares-Garita, C. (2016). Red de liderazgo pedagógico como una herramienta dialógica entre la Universidad Nacional, Sede Regional Brunca y comunidad local. Revista Universidad en Diálogo, 6 (1), pp. 47-46. http://dx.doi.org/10.15359/udre.6-1.3

Bolívar, A. (2015). Un liderazgo pedagógico en una comunidad que aprende. Padres y maestros, (361), 23-27. https://doi.org/10.14422/pym.i361.y2015.004

Castillo, M. (2010). La profesión docente. Revista Médica de Chile, 138(7), 902-907. http://redalyc.uaemex. $\mathrm{mx} / \mathrm{src} /$ inicio/ArtPdfRed.jsp?iCve=177116633015

Cerquera-Flórez, A. R., Corredor-Medina, F., Cuero-Mosquera, C. A., Rivera-Sierra, V. A, y Castro-Pérez, Z. C. (2016). Sentido y Significado de ser Docente: Reflexiones para re-pensar la educación. Plumilla Educativa, 18(2), 303-317. https://doi.org/10.30554/plumillaedu.18.1970.2016

Contreras, T. S. (2016). Liderazgo pedagógico, liderazgo docente y su papel en la mejora de la escuela: una aproximación teórica. Propósitos y representaciones, 4(2), 231-284.

Cuevas-Cajiga, Y. y Moreno-Olivos, T. (2016). Políticas de evaluación docente de la OCDE: Un acercamiento a la experiencia en la educación básica mexicana. Archivos Analíticos de Políticas Educativas, 24(120). http://dx.doi.org/10.14507/epaa.24.2283

Díez-Gutiérrez, E. J. (2016). La educación de la nueva subjetividad neoliberal. Revista lberoamericana de Educación, 68(2), 157-172. https://doi.org/10.35362/rie682190

Duarte, J. (2007). Formación permanente de docentes en servicio alternativa para la enseñanza y el aprendizaje de la lengua escrita en la educación básica integral (Tesis Doctoral). Universitat Rovira i Virgili, Tarragona, España. https://www.tdx.cat/bitstream/handle/10803/8931/2AMBITOCONCEPTUALI. pdf? sequence $=3 \&$ isAllowed $=y$

Ennser-Kananen, J., Escobar, C. F., y Bigelow, M. (2017). "It's Practically a Must": Neoliberal Reasons for Foreign Language Learning. International Journal of Society, Culture and Language, 5, 15-28. https:// jyx.jyu.fi/bitstream/handle/123456789/54868/1/ennserkananenescobarbigelowitspractivally.pdf

Freire, P. (1985). La naturaleza política de la educación: Cultura, poder y liberación. Barcelona: Centro de Publicaciones del Ministerio de Educación y Ciencia y Ediciones Paidós Ibérica, S.A.

Freire, P. (1987). La Educación como práctica de la libertad. D.F., México: Andrómeda.

Galindo, C., Gómez, J., y Rodríguez, M. (2015). Repercusión del proyecto neoliberal en la educación superior en Colombia. El Ágora USB, 15(1), 73-94. https://doi.org/10.21500/16578031.3 
Giglioli, G. (1996). Los intelectuales orgánicos en la teoría de Gramsci. Reflexiones, 46(1), 2. https://dialnet. unirioja.es/descarga/articulo/4796039.pdf

Giraldo, G. D., y Naranjo, A. J. (2014). Liderazgo: Desarrollo del concepto, evolución y tendencias. Estudio monográfico. Universidad del Rosario. Bogotá, Colombia. https://repository.urosario.edu.co/bitstream/handle/10336/8672/1026275656-2014.pdf?sequence=1

Gramsci, A. (1967). La formación de los intelectuales. México: Grijalbo. https://proletarios.org/books/ Gramsci-La_formacion_de_los_intelectuales.pdf

Grossman, P., Wineburg, S., y Woolworth, S. (2001). Toward a theory of teacher community. The teachers college record, 103, 942-1012. http://www.tcrecord.org/Content.asp?ContentID=10833

Little, J. W. (2003). Inside teacher community: Representations of classroom practice. Teachers College Record, 105(6), 913-945. https://www.researchgate.net/profile/Judith_Warren_Little/publication/280017903_Inside_Teacher_Community_Representations_of_Classroom_Practice/ links/575acd4c08aed884620d917d/Inside-Teacher-Community-Representations-of-ClassroomPractice.pdf

López Guerra, S., y Flores-Chávez, M. (2006). Las reformas educativas neoliberales en Latinoamérica. Revista electrónica de investigación educativa, 8(1), 1-15. http://www.scielo.org.mx/scielo. php?script=sci_arttext\&pid=S1607-40412006000100006\&lng=es\&tlng=es

Magalhães, S. M. de O., Araujo, S., y Argüello, S. B. (2020). Agudización ultra neoliberal, educación y formación docente en Brasil y Argentina. Revista Inter Ação, 45(1), 49-80. https://doi.org/10.5216/ ia.v45i1.62687

Marx, C. y Engels, F. (1974). La ideología alemana. Ediciones Grijalbo. https://proletarios.org/books/ Marx-Ideologia_alemana.pdf

Nietzsche, F. W. (1999). Schopenhauer como educador: tercera consideración intempestiva (Moreno-Claros, W). Madrid: Valdemar (Obra original publicada en 1874). Valdemar.

Puiggrós, A. (1996). Educación neoliberal y quiebre educativo. Nueva Sociedad, 146, 90-101. http:// invexped.udistrital.edu.co:8080/documents/40587/88535/educacion+neoliberal+y+quiebre+e ducativo.pdf

Robinson, K., y Aronica, L. (2016). Creative schools: The grassroots revolution that's transforming education. Penguin books.

Rodríguez-Mancilla, H. M., Betancourt-Sáez, M. E., y Varas-González, R. A. (2018). La episteme neoliberal y la repolitización estudiantil emancipatoria en Brasil y Chile. Sophia, colección de Filosofía de la Educación, (25), 259-286. http://dx.doi.org/10.17163/soph.n25.2018.09

Rodríguez-Molina, G. (2011). Funciones y rasgos del liderazgo pedagógico en los centros de enseñanza. Educación y Educadores, 14(2), 253-267. https://www.redalyc.org/pdf/834/83421404003.pdf.

Santa Cruz-Grau, E. y Olmedo, A. (2012). Neoliberalismo y creación de "sentido común": Crisis educativa y medios de comunicación en Chile. Revista de Currículum y Formación de Profesorado, 16(3), 167190. https://recyt.fecyt.es/index.php/profesorado/article/view/42704

Solano, W., y Campos, J. (2014). Hacia la construcción de un perfil para el docente del futuro. Innovaciones Educativas, 16(21), 85-107. https://doi.org/10.22458/ie.v16i21.904

Solano-Muñoz, E. (2010). La crisis contemporánea de la financiación de la Educación Superior Pública en Costa Rica: un eslabón más de la estrategia neoliberal. Actualidades Investigativas en Educación, 10, 1--20. https://revistas.ucr.ac.cr/index.php/aie/article/download/10159/18016

Sun, T. (2016). El arte de la guerra. Aegitas.

Torres, C. A. (2008). Después de la tormenta neoliberal: la política educativa latinoamericana entre la crítica y la utopía. Revista Iberoamericana de Educación, 48, 207-229. https://doi.org/10.35362/rie480697 